\title{
Esthetic Evaluation and Acceptability of Different Hole Designs on Implant Crowns from the Perspective of Patients and Dentists in China
}

\author{
Cai Wen $\mathbb{D}^{1-3}$, Rong Jiang $\mathbb{D}^{4}$, Zhiqiang Zhang $\mathbb{D}^{4}$, Bo Lei $\mathbb{D}^{4}$, Yingquan Zhong $\mathbb{D}^{4}$, Huangjun Zhou $\mathbb{D}^{1,3}$ \\ 'Department of Oral Implantology, The Affiliated Stomatology Hospital of Southwest Medical University, Luzhou, Sichuan, People's Republic of China; \\ ${ }^{2}$ Department of VIP Dental Service, The Affiliated Stomatology Hospital of Southwest Medical University, Luzhou, Sichuan, People's Republic of \\ China; ${ }^{3}$ Orofacial Reconstruction and Regeneration Laboratory, The Affiliated Stomatology Hospital of Southwest Medical University, Luzhou, Sichuan, \\ People's Republic of China; ${ }^{4}$ Department of Dentistry, People's Hospital of Aba Tibetan and Qiang Autonomous Prefecture, Ma'erkang, Sichuan, \\ People's Republic of China
}

Correspondence: Cai Wen, Department of Oral Implantology, The Affiliated Stomatology Hospital of Southwest Medical University, Luzhou, Sichuan, People's Republic of China, Email wencai@swmu.edu.cn

Purpose: Abutment access hole on dental implant crowns may facilitate crown retrieval and reduce cement overflow but present esthetic obstacle for patients. This study aimed to investigate the esthetic evaluation and acceptability of implant crowns with different hole designs from the perspective of patients and dentists.

Materials and Methods: Anterior and posterior implant zirconia crowns were fabricated into three types: no hole (NH), $1 \mathrm{~mm}$ micro hole $(\mathrm{MH})$, and $2.5 \mathrm{~mm}$ regular hole $(\mathrm{RH})$. The $\mathrm{NH}$ crown was set as the control, and the anterior and posterior crowns with $\mathrm{MH}$ and $\mathrm{RH}$ were evaluated. The subjects, who were recruited randomly, were comprised of lay patients $(\mathrm{n}=60)$ and professional dentists $(n=30)$. All subjects were invited to evaluate the esthetic performance of MH and RH crowns on a Visual Analog Scale (VAS), rate them from 0 to 10, state their acceptability of these crowns, and label them as acceptable and unacceptable.

Results: The ANOVA analysis of the VAS esthetic evaluation showed that the size of the hole, the position of the teeth, and the professional background of the subject significantly and independently affected esthetic perception. Crowns with MH in the posterior position had higher esthetic scores and acceptability compared with crowns with RH in the anterior position, and dentists tended to show higher acceptance and better esthetic rating for crowns with holes compared with lay patients.

Conclusion: The hypothesis that patients and dentists hold similar esthetic evaluations or acceptability towards implant crown hole designs was rejected. Lay patients had a lower tolerance for venting holes than dentists. Crowns with 1 mm micro holes were more recommendable than crowns with regular abutment access holes from the point of view of satisfying patients' esthetic needs.

Keywords: implant crown hole, visual analog scale, esthetic adherence, abutment access hole

\section{Introduction}

With the continuous development of oral implantology, restorations supported by dental implants have become the mainstream option for patients with dentition defects. Generally, there is a slight morphological difference between implant-supported crowns and ordinary prosthodontic crowns. ${ }^{1}$ In particular, there may be abutment access holes on the implant crown, which may present esthetic obstacles for both prosthodontists and patients.

For screw-retained implant restoration, it is compulsory to leave abutment access holes, while for cement-retained implant restoration, leaving holes is optional. ${ }^{2}$ Screw-retained restoration has the advantage of leaving no cement residue, but it has disadvantages of worse aesthetics, more structural components, higher prosthodontics costs, and make it more difficult to get a passive fit compared with cement-retained restoration. ${ }^{3}$ Consequently, cement-retained implant restorations are still widely used in clinical practice. The decision, whether to leave a hole or not for a cement-retained crown and its diameter, is mostly made by dentists subjectively. Creating a hole on a cement-retained implant crown would decrease excess cement extrusion at the abutment margin when cementing and could also serve as a marker for an 
abutment screw when retrieval is necessary. ${ }^{4-7}$ Since patients are generally not knowledgeable when it comes to oral implantology, they often ask questions when they see the hole on the crown for the first time. Although they will passively accept the crown, these patients are usually dissatisfied with the esthetic results. In other studies, the techniques for hole opening on implant crowns have been discussed, but most of them only explored their advantages for residual cement reduction. ${ }^{8-11}$ Patient-centered studies focusing on esthetic perceptions of implant crown hole designs, from the perspective of patients and dentists, are still lacking.

Clinical aesthetic evaluations of the oral cavity can be divided into objective and subjective evaluations. For objective evaluations, anatomical markers, such as the marginal bone loss (MBL) ${ }^{12}$ and pink esthetic score (PES), and technical features of the prosthesis, such as evaluating the optical properties, ${ }^{13}$ are generally used. Subjective evaluations are usually obtained through interviews and surveys. ${ }^{14}$ The visual analog scale ${ }^{15-17}$ is a simplified and visualized questionnaire survey, allowing participants to avoid filling out a complex questionnaire. They are used in esthetic and satisfaction evaluations for their convenience, objectivity, and sensitivity.

The first goal of this study was to establish the esthetic evaluation and acceptability of implant crowns with different hole designs from the viewpoints of both patients and dentists. The second goal was to verify the null hypothesis that patients and dentists have similar esthetic perceptions and acceptability.

\section{Materials and Methods}

\section{Production of Evaluation Samples}

Anterior and posterior groups of cement-retained implant crowns were included in this study. Three types of crowns were fabricated in each group: no hole (NH), micro hole ( $\mathrm{MH}$ : hole $1 \mathrm{~mm}$ in diameter), and regular hole (RH: hole $2.5 \mathrm{~mm}$ in diameter). The crowns and casts were fabricated by a dental laboratory, and all casts were fabricated by digital printing to eliminate bias caused by plaster casts. Virtual implants were generated by 3Shape software (3Shape, Copenhagen, Denmark) at a suitable position for teeth $\# 11$ and $\# 26$ on a standard digital denture cast on a computer. The morphologies of teeth \#11 and \#26 were generated using the mirror images of teeth \#21 and \#16, and artificial gingival were produced and embedded in the cast at the same time. Titanium made, straight abutments (Dentium, Seoul, South Korea), zirconia blocks, and veneering porcelain were used to fabricate the bi-layered crowns, and the $2 \mathrm{M} 3$ color was chosen based on the Vita System 3D-Master tooth shade system. Six types of implant crowns were fabricated as follows: A: anterior crown, no hole (ANH); B: anterior crown, micro hole (AMH); C: anterior crown, regular hole (ARH); D: posterior crown, no hole (PNH); E: posterior crown, micro hole (PMH); and F: posterior crown, regular hole (PRH). Figure 1 shows the casts with implant crowns and lingual and occlusal views of the crowns before composite resin filling of the holes. The crowns in each group had the same morphology and color but their hole opening designs varied.

The crowns were cemented by Temporary adhesive (Temp-bond, Kerr, CA, USA) which ensured that they were fully seated on the implant abutments. For groups with micro and regular holes, composite resin (3M, USA) was used to fill the access holes, and the surface of the crown was polished after light curing. Figure 2 shows that the crown holes were filled with composite resin.

\section{Ethical Review}

The survey was censored by the ethics committee of the People's Hospital of Aba Tibetan and Qiang Autonomous Prefecture. The interview nature of the research has no intervention or interaction with the human body. The risk of the research to subjects was less than the minimal risk and does not adversely affect their rights and health. Owing to the signed consent form will jeopardize the subjects' personal privacy, and the only record to contact their identity is the informed consent document, and the main risk comes from the disclosure of the subjects' identity or personal privacy. The ethics committee approved the research and granted an exemption from written informed consent, and written notification and verbal informed consent were required (Approval number, No.2021, 21). The study was conducted in accordance with the Declaration of Helsinki. Prior to commencement, we provided written notification information to and obtained oral informed consent from each participant. After completing survey, the age, gender and informed consent result of all subjects were recorded. 

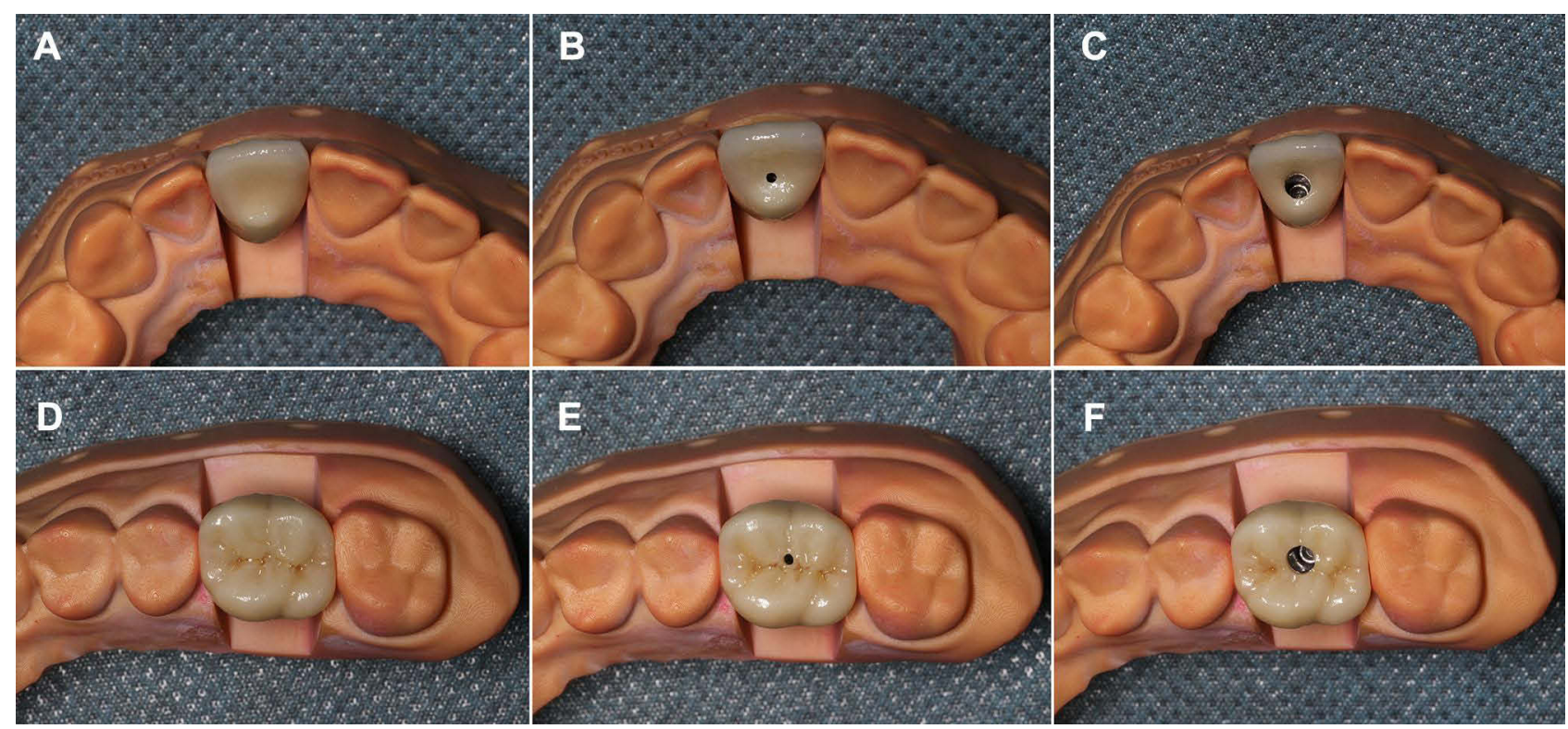

Figure I The lingual and occlusal views of crowns on casts with different access hole designs (without resin filling of the holes). (A) anterior crown, no hole (ANH); (B) anterior crown, micro hole (AMH); (C) anterior crown, regular hole (ARH); (D) posterior crown, no hole (PNH); (E) posterior crown, micro hole (PMH); (F) posterior crown, regular hole $(\mathrm{PRH})$.

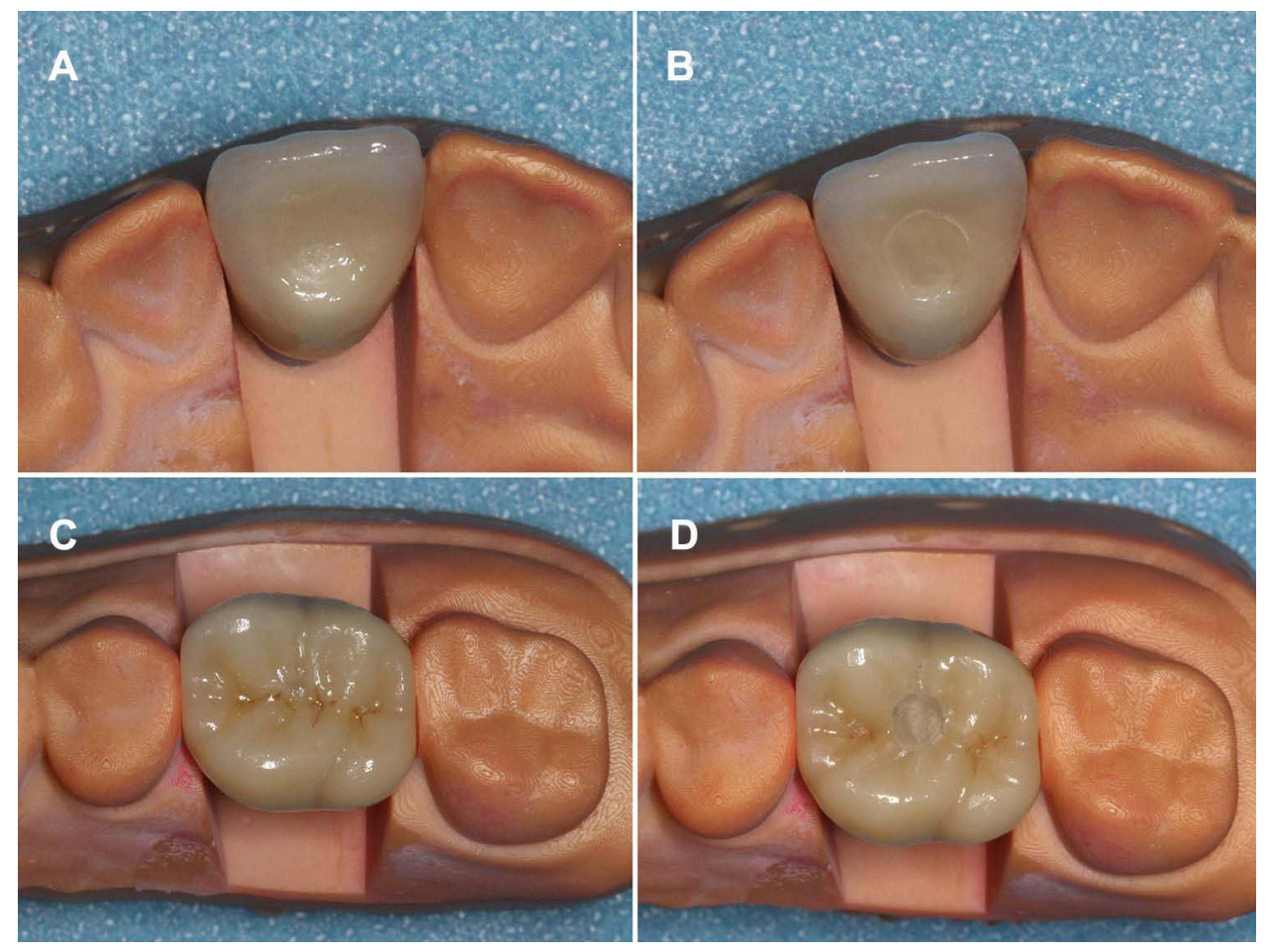

Figure 2 Crown holes filled by composite resin: (A) AMH; (B) ARH; (C) $\mathrm{PMH}$; (D) PRH.

\section{Subject Survey}

The patient and dentist subjects were randomly enrolled from those visiting or employed in the dental departments in hospitals and clinics. All surveyed subjects were over 18 years old, could fully understand the Mandarin language and instructions given in Mandarin, and in the case of dentist subjects, were either general practitioners or prosthodontists who had experience in dental prosthodontic restoration. 


\section{What do you think of the esthetic result of the implant crown?}

\section{1.with Micro/smaller hole}

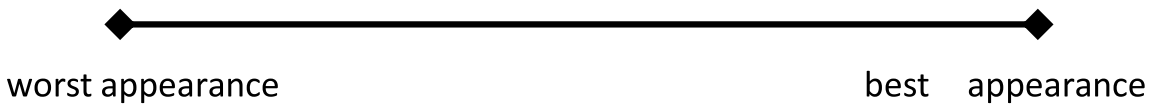

Acceptability: $\quad$ No Yes

\section{2.with Regular/bigger hole}

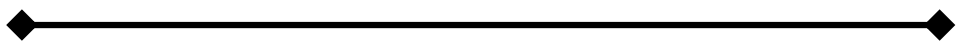

worst appearance

best appearance

Acceptability: $\quad$ No Yes

Figure 3 Esthetic Visual Analog Scale (VAS) survey card for subjects (eg, VAS comparison between micro hole and regular hole designs for posterior teeth).

All subjects were informed in advance that no conflict of interest existed, written notification was provided, and we obtained verbal informed consent from each subject. The evaluation order of the anterior and posterior teeth groups was determined by coin tossing. Three types of implant crowns (NH, MH, RH) were given to subjects initially, and they were asked to evaluate their esthetic scores on a Visual Analog Scale (VAS) based on their views, focusing only on the differences in hole designs. The $10 \mathrm{~cm}$ VAS sheet was used to assess the esthetic value of the crowns, and subjects were asked to place a mark on the sheet to grant an esthetic value score. The NH crown was set as the control, and only the micro hole $(\mathrm{MH})$ and regular hole $(\mathrm{RH})$ crowns were evaluated. Subjects were informed that a score of 0 indicated the worst esthetic performance, and a score of 10 would correspond to perfect esthetic performance. The investigator then measured the distance from the leftmost end of the VAS to the marked place to determine the esthetic value (Figure 3). After the esthetic evaluation of these groups, investigators informed the lay and professional subjects of the functions of these holes, and all subjects were asked to state their acceptability of these crowns with micro holes or regular holes, and label them as acceptable and unacceptable.

\section{Reliability Assessment}

To assess the reliability of the survey, about $20 \%$ of the lay patients and $40 \%$ of the dentists were asked to evaluate the same two groups of crowns a second time, and were not informed that they were evaluating the same crowns.

\section{Data Statistics}

The reliability of both subject groups was calculated using the intraclass correlation coefficient for the esthetic VAS scores and the kappa statistic was used for acceptability data. Statistical analysis was performed using SPSS version 19.0 (SPSS Inc.).

Analysis was performed using either Student's $t$-test for comparison between patients and dentists' groups, or factorial analysis of variance for multiple comparisons among them. Acceptability data were analyzed using Pearson's chi-squared test. The Kolmogorov-Smirnov test was used to confirm the normal distribution of the data. Results were considered statistically significant if the $\mathrm{P}$ value was $<0.05$.

\section{Results}

A total of 60 lay patients and 30 professional dentists participated in this study. Among the patients, 28 were male and 32 were female; and among the dentists, 18 were male and 12 were female. The age and gender composition of the 


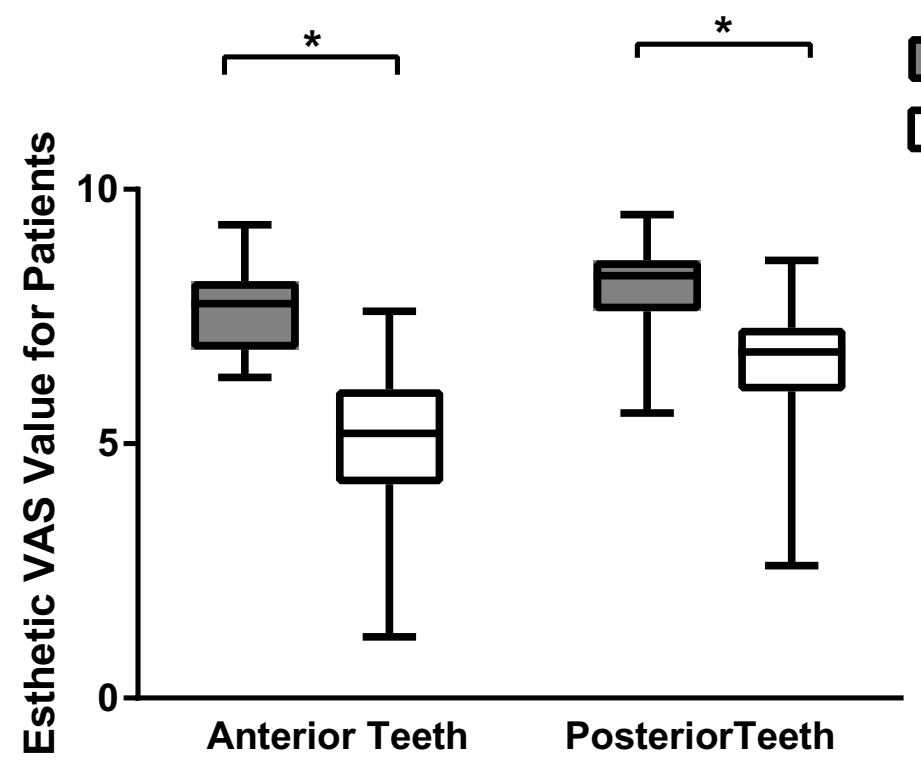

Figure 4 Esthetic VAS scores of implant crowns with $\mathrm{MH}$ and $\mathrm{RH}$ in anterior and posterior teeth groups for patients, *Represents significant difference.

participants are shown in Table 1. There was no statistical difference in the composition ratio of gender and age between the two groups $(\mathrm{p}>0.05)$. The VAS and acceptability data were normally distributed. The intra-rater reliability of the esthetic VAS result was good in both the patient and dentist groups, with intra-rater correlation coefficients of 0.938 and 0.908 , respectively. For acceptability data, the kappa values were $0.759(\mathrm{p}<0.001)$ and $0.639(\mathrm{p}<0.001)$ for the patient and dentist groups, respectively, which indicated good reliability.

For the anterior teeth group, the esthetic VAS scores graded by the patients were $7.62 \pm 0.80$ and $5.14 \pm 1.35$ for AMH and ARH, respectively; the esthetic VAS scores graded by the dentists were $8.90 \pm 0.62$ and $7.13 \pm 1.40$, respectively; and thus, the independent two-sample $t$-test demonstrated a significant difference $(\mathrm{p}<0.001)$. For the posterior teeth group, the patients' esthetic VAS scores were $8.12 \pm 0.74$ and $6.55 \pm 1.27$ for PMH and PRH, respectively; the dentists' were 9.05 \pm 0.43 and $7.39 \pm 1.09$, respectively; a significant difference was also revealed $(\mathrm{p}<0.001)$ (Table 2, Figures 4 and 5). Regarding the acceptability by patients and dentists of the openings, the acceptability of AMH and ARH were $90.0 \%$ and $51.7 \%$, respectively, for patients; and $100.0 \%$ and $76.7 \%$, respectively, for dentists. Meanwhile, the acceptability of PMH and PRH were $96.7 \%$ and $68.3 \%$, respectively, for patients; and $100.0 \%$ and $83.3 \%$, respectively, for dentists (Table 2).

The factorial ANOVA revealed that the three variables (the position of teeth, size of the hole, and the professional background of the surveyed subjects) independently affected the main effect of the esthetic VAS score significantly. The interactions between teeth position and hole sizes and between teeth position and surveyed subjects also significantly

Table I Demographic Characteristics of the Raters Who Participated in This Study

\begin{tabular}{|l|l|l|}
\hline Characteristic & Lay Patients (n/\%) & Dentists (n/\%) \\
\hline $\begin{array}{l}\text { Gender groups } \\
\text { Male }\end{array}$ & $28(46.7)$ & $18(60.0)$ \\
Female & $32(53.3)$ & $12(40.0)$ \\
\hline Age groups & & \\
$18-30$ & $16(26.7)$ & $6(20.0)$ \\
$31-45$ & $30(50.0)$ & $13(43.3)$ \\
$46-60$ & $14(23.3)$ & $11(36.7)$ \\
\hline
\end{tabular}


Table 2 Esthetic and Acceptability Score from Lay Patients and Dentists in Anterior and Posterior Teeth Groups

\begin{tabular}{|l|l|l|l|l|}
\hline \multirow{2}{*}{} & \multicolumn{2}{|c|}{ Lay Patients } & \multicolumn{2}{c|}{ Dentists } \\
\cline { 2 - 5 } & VAS Score & Acceptability (\%) & VAS Score & Acceptability (\%) \\
\hline Groups (Anterior) & & & & \\
Anterior micro hole group & $7.62 \pm 0.80$ & 90.0 & $8.90 \pm 0.62$ & 100.0 \\
Anterior regular hole group & $5.14 \pm 1.35$ & 51.7 & $7.13 \pm 1.40$ & 76.7 \\
P value & $<0.001$ & $<0.001$ & $<0.001$ & $<0.001$ \\
\hline Groups (Posterior) & & & & \\
Posterior micro hole group & $8.12 \pm 0.74$ & 96.7 & $9.05 \pm 0.43$ & 100.0 \\
Posterior regular hole group & $6.55 \pm 1.27$ & 68.3 & $7.39 \pm 1.09$ & 83.3 \\
P value & $<0.001$ & 0.016 & $<0.001$ & 0.062 \\
\hline
\end{tabular}

affected the esthetic VAS scores $(\mathrm{p}<0.05)$. Table 3 describes the main effects and interactions in the 3 -way classification ANOVA.

\section{Discussion}

There are two types of retention forms for implant-supported crowns: screw and cement. Screw-retained restoration could completely avoid cement residue, but it displays more mechanical complications, such as screw loosening or fracture. ${ }^{5,18}$ In the case of screw-retained crowns, they would have a screw access hole as a channel to fasten or retrieve the abutment. Cement-retained crowns have the advantage of lower cost and more convenient fabrication procedures, and it is easier to achieve passive fit between the abutment and the crown. Although cement-retained crowns are favored by dentists, their shortcomings are obvious: when they need to be retrieved, the crowns have to be broken, ${ }^{1,10,19}$ excess cement residue underneath the gingiva is difficult or impossible to avoid, ${ }^{20,21}$ and such excess cement may lead to periimplant disease. ${ }^{22}$ Therefore, previous studies have reported various methods for reducing residual cement around the abutment margin of cement-retained implant crowns, such as making venting holes, ${ }^{23-27}$ using polytetrafluoroethylene tape ${ }^{28,29}$ or a rubber dam, ${ }^{30}$ reducing the amount of cement applied, ${ }^{31}$ modifying the shape of the abutment ${ }^{32}$ or

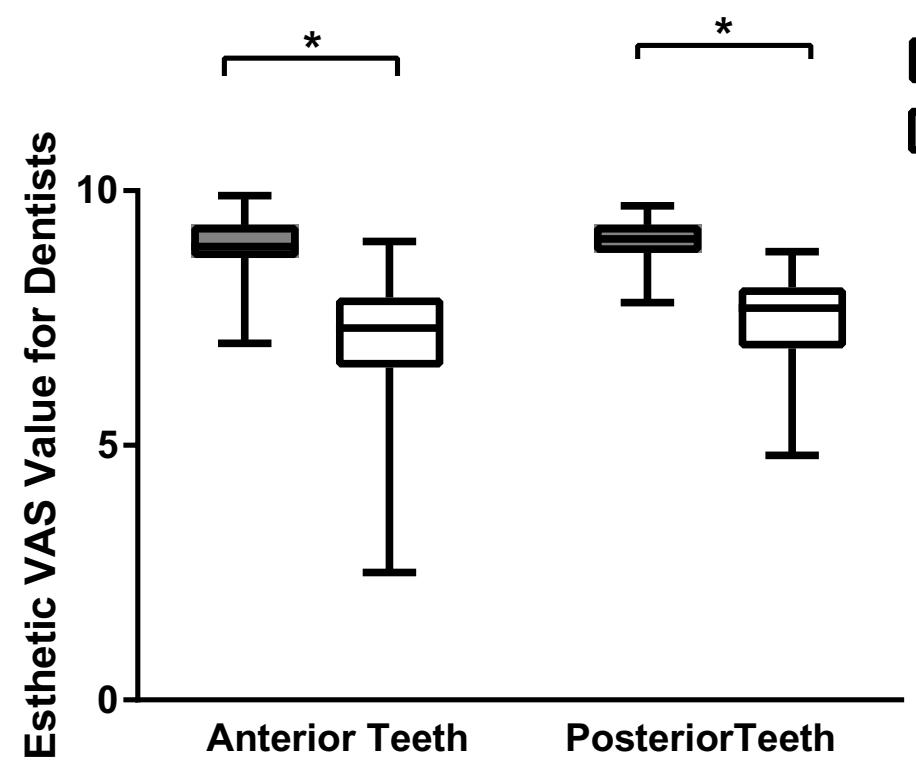

Figure 5 Esthetic VAS scores of implant crowns with $\mathrm{MH}$ and $\mathrm{RH}$ in anterior and posterior teeth groups for dentists, *Represents significant difference. 
Table 3 Factorial Variance Analysis of Esthetic Evaluation of Implant Crowns

\begin{tabular}{|c|c|c|c|c|c|}
\hline Source of Variation & Type III Sum of Squares & Degree of Freedom & Mean Square & $\boldsymbol{F}$ & $\mathbf{p}$ \\
\hline Teeth Position & 28.840 & I & 28.840 & 26.769 & 0.000 \\
\hline Hole Size & 287.156 & $\mathrm{I}$ & 287.156 & 266.533 & 0.000 \\
\hline Subjects & 123.091 & $\mathrm{I}$ & $123.09 \mid$ & $|14.25|$ & 0.000 \\
\hline Teeth Position*Hole Size & 6.479 & I & 6.479 & 6.014 & 0.015 \\
\hline Teeth Position*Subjects & 9.545 & $\mathrm{I}$ & 9.545 & 8.860 & 0.003 \\
\hline Hole Size*Subjects & 1.275 & I & 1.275 & 1.184 & 0.277 \\
\hline Teeth Position*Hole Size*Subjects & 2.677 & 1 & 2.677 & 2.484 & 0.116 \\
\hline Error & 379.236 & 352 & 1.077 & & \\
\hline Corrected Total & 19914.000 & 359 & & & \\
\hline
\end{tabular}

increasing the unfilled space of the abutment, ${ }^{33,34}$ using the pre-seating technique ${ }^{19,35}$ by accustomed abutment duplication, avoiding placing the crowns' restorative margin into a deep place underneath the gingiva ${ }^{36}$ and so on.

Of all these methods, leaving a hole on the crown is the simplest approach to minimize marginal extrusion without reducing the retention force, ${ }^{7}$ and the hole can also serve as a marker for the abutment screw direction and facilitate retrieval of the crown. Although creating a hole on the crown seems like a convenient way to obtain a double advantage, it will certainly damage the integrity of the restoration and may cause deterioration of the esthetic result. Previous studies ${ }^{11,37,38}$ showed that screw access holes on implant crowns had an adverse effect on esthetic results and weakened the porcelain strength around the holes. Composite resins ${ }^{8,39}$ were the most commonly used material for filling the holes on crowns, and ceramic inlay restorations ${ }^{37}$ and separate overcasting crowns ${ }^{38}$ were also designed to fill holes and improve esthetic results. In clinical practice, composite resin is generally layered and stacked to obtain better esthetic results and edge closure. ${ }^{37,40}$ However, these commonly used filling materials are mainly semi-translucent and cannot completely cover the dark metal grounding inside the hole and the composite resin also has a negative influence on prosthodontic esthetic results. ${ }^{39}$ Weininger et a ${ }^{41}$ found that using a small amount of opaquer with the hole filling material could improve esthetic results. Taylor et $\mathrm{al}^{11}$ indicated that composite resins have been widely used in the filling of access openings for implant prostheses, and the expansion properties of panacea resin (Zeza Inc., Chester, USA) can help remedy the leakage of bacterial contaminants around the screw access hole.

VAS is a unidimensional, self-reported measure of subjective sensation that has been used in esthetic evaluations. It has been used to analyze factors affecting implant esthetics owing to its convenience and repeatability. ${ }^{15,42}$ In this study, a repeatability test was conducted, its consistency was evaluated, and the results demonstrated that repeatability and reliability were good. Further, in this study, the esthetic evaluation of MH by lay patients and dentists was significantly higher than that of RH in the anterior and posterior teeth. Both the implant professionals and lay patients awarded the highest VAS score to the posterior micro hole group, while they gave lower scores as the size of the hole increased and the position of the tooth moved toward the anterior. Professionals and lay patients awarded the lowest VAS score to the anterior regular hole group. This tendency might be that the lingual area of the anterior teeth is smaller than the occlusal area of the posterior teeth, so holes of the same size account for a larger proportion of the anterior teeth. Holes on the anterior teeth may cause an abnormal tactile sensation in the tongue, while holes on the posterior teeth are in the occlusal region and generally will not cause abnormal tongue sensation.

Based on the results of this study, the null hypothesis that lay patients and dentists hold similar esthetic evaluation scores for and acceptability towards implant crowns with holes was rejected: dentists viewed implant restorations with holes as having better esthetic results, and deemed these restorations to be more acceptable than lay patients did. Compared with professionals, lay patients had a lower tolerance for holes on crowns. The reason may be that dentists were more familiar with the hole designs and were more likely to accept these holes based on their practicality. Further, dentists may pay more attention to excess cement avoidance, long-term survival of implants, complications, and ease of retrieval rather than esthetic concerns. However, patients tended to be more critical of the esthetic result and their long-standing dentition defects and economic expenditure increased their esthetic expectations. The increased scrutiny of patients compared with dentists can also be 
supported by the fact that dentists rated $1.28,1.99,0.93$, and 0.89 points higher than lay patients in the mean VAS esthetic scores of crowns in the AMH, ARH, PMH, and PRH groups, respectively.

The results of this study were contrary to some previous works ${ }^{43-45}$ which indicated that professionals were more likely to distinguish esthetic compromises in dentition compared with laypeople. The reason for this is that most previous studies mainly analyzed professional esthetic indicators such as the cutting edge length of incisors, gingiva edge position, red and white esthetics, anatomical morphology of teeth, width-to-height ratio, and so on. It was difficult for laypeople to understand these indicators and to detect their differences in the short term. In the case of the crown holes, they were obvious and it was easy for patients to detect differences in their design. Different research content and indicators may explain the contrasting results of studies on esthetic sensitivity and tolerance between professionals and laypeople.

Since patients and dentists have different esthetic concerns regarding hole designs, dentists should establish how best to balance requests for the esthetic results of implant crowns, the convenience of crown retrieval, and the reduction of excess cement residue underneath the gingiva. ${ }^{46,47}$

Although dentists may take the existence of implant crown access holes for granted, most patients might not be aware of the possible existence of a hole on their implant crown when they begin the treatment. The existence of a hole on the crown may produce a sense of a foreign body for patients. Therefore, before prosthodontic procedures and even before implant treatment, communication and discussion between implantists, prosthodontists, and patients are needed to obtain better treatment and satisfaction results. Due to the size of the hole on the crown dramatically affecting patients' esthetic perceptions, leaving a tiny or micro hole on the crown would minimize its impact on esthetics and improve patients' acceptance of the crown. Moreover, a micro hole on the crown maintains its integrity to the maximum extent and provides better resistance to fracture compared with the regular larger hole. Saboury et $\mathrm{al}^{48}$ indicated that a screw access hole decreased the fracture resistance of the crown. Another study by Du et a ${ }^{49}$ indicated that a full-contour crown with a $1-\mathrm{mm}$ access hole should be recommended more than holes with diameters of $0,1,2,3$, and $4 \mathrm{~mm}$ in the posterior region from the aspect of biomechanics. In addition, the technique of leaving a micro hole on the crown was even more advantageous considering that the dilemma of the retrieval of cement-retained implant crowns would be greatly simplified. Dentists were only required to slightly enlarge the hole when the crown needed retrieval, and the time spent on retrieval would be greatly reduced compared to crowns without markers. Schoenbaum et al ${ }^{50}$ reported another way to mark the abutment access by using color stain on the surface of the restoration. However, the stain would also negatively affect the esthetic performance of the crown and would have no effect on excess cement extrusion avoidance. Patients generally expect a smaller hole on an occlusal surface with a resin color that more closely resembles the color of the restoration and adjacent teeth. Therefore, opening a micro hole may still be the most effective and cost-effective way to reduce complications and improve the ease and predictability of future crown retrieval. Considering esthetic and biomechanical performance, micro holes for implant cement-retained crowns are efficient, effective, and widely applicable.

Shortcomings of this study: This study was mostly carried out in China's ethnic minority areas of the Aba Tibetan and Qiang autonomous prefecture. This autonomous prefecture is an area with relatively underdeveloped economic level and medical service, which can exclude the impact of medical advertising and other factors on patients' cognition. The main populations there are Tibetan, Qiang, and Han, with relatively average ethnic composition, and most inhabitants can communicate in the Mandarin language. Thus, during our random enrollment of subjects, there was no stratified sampling according to ethnic background. In this anonymous survey, we did not record the subjects' ethnic background, and a comparison based on ethnic background was not conducted. Future studies on esthetic evaluation of implant crowns should be conducted with larger sample sizes and more tooth positions.

\section{Conclusion}

This study revealed that patients and dentists detected esthetic differences and held different degrees of acceptability toward implant crowns with different holes. Dentists awarded implant crowns with holes with better esthetic scores and demonstrated greater acceptability of them compared to lay patients. Based on higher acceptance and better esthetic performance of implant crowns with micro holes, they were more recommendable than crowns with regular abutment access holes. Before and during treatment, communication and discussion between dentists and patients are needed to obtain greater consensus and better satisfaction results. 


\section{Abbreviations}

$\mathrm{AMH}$, anterior crown, micro hole; $\mathrm{ANH}$, anterior crown, no hole; $\mathrm{ARH}$, anterior crown, regular hole; $\mathrm{MH}$, micro hole; $\mathrm{NH}$, no hole; $\mathrm{PMH}$, posterior crown, micro hole; $\mathrm{PNH}$, posterior crown, no hole; $\mathrm{PRH}$, posterior crown, regular hole; RH, regular hole; VAS, visual analog scale.

\section{Data Sharing Statement}

Further information on the data set and materials is available from the corresponding author upon reasonable request.

\section{Ethics Approval and Informed Consent}

The survey was censored by the ethics committee of the People's Hospital of Aba Tibetan and Qiang Autonomous Prefecture. The risk of the research to subjects was less than the minimal risk and does not adversely affect their rights and health. Owing to the signed consent form will jeopardize the subjects' personal privacy, and the only record to contact their identity is the informed consent document, and the main risk comes from the disclosure of the subjects' identity or personal privacy. The ethics committee approved the research and granted an exemption from written informed consent, and written notification and verbal informed consent were required (Approval number: 2021, 21).

\section{Acknowledgments}

The author Cai Wen thanks the people of Aba Tibetan and Qiang Autonomous Prefecture for their assistance during his one-year health poverty alleviation work.

\section{Funding}

This work was supported by grants from the Southwest Medical University, No. 2020ZRZD016; Medical Association of Sichuan Province, No. S18079; Sichuan Provincial Department of Education, NO. 18ZA0526; and Strategic cooperation project between Sichuan University and Luzhou Municipal Government, No.2018CDLZ-14.

\section{Disclosure}

The authors declare that they have no competing interests.

\section{References}

1. Wittneben JG, Joda T, Weber HP, Bragger U. Screw retained vs. cement retained implant-supported fixed dental prosthesis. Periodontol 2000. 2017;73(1):141-151. doi:10.1111/prd.12168

2. Shadid R, Sadaqa N. A comparison between screw- and cement-retained implant prostheses. A literature review. J Oral Implantol. 2012;38 (3):298-307. doi:10.1563/AAID-JOI-D-10-00146

3. Özcan M, Malpartida-Carrillo V, Ortiz-Culca F, Guerrero ME, Amaya-Pajares SP, Tinedo-López PL. Fracture resistance of cement-retained, screw-retained, and combined cement- and screw-retained metal-ceramic implant-supported molar restorations. J Contemp Dent Pract. 2020;21 (8):868-873. doi:10.5005/jp-journals-10024-2884

4. Davoudi A, Rismanchian M. Effects of modifying implant screw access channels on the amount of extruded excess cement and retention of cement-retained implant-supported dental prostheses: a systematic review. J Prosthet Dent. 2019;121(1):52-58. doi:10.1016/j.prosdent.2018.03.002

5. Lemos CA, de Souza Batista VE, Almeida DA, Santiago Junior JF, Verri FR, Pellizzer EP. Evaluation of cement-retained versus screw-retained implant-supported restorations for marginal bone loss: a systematic review and meta-analysis. J Prosthet Dent. 2016;115(4):419-427. doi:10.1016/ j.prosdent.2015.08.026

6. Sun B, Li Y, Wang Y, Zhou Q. Adhesion properties of modified cement-retained implant prostheses: in vitro mechanical tensile experiments and computational fluid dynamics analyses. J Prosthet Dent. 2020;123(2):290 e291-290 e298. doi:10.1016/j.prosdent.2019.10.008

7. Wang F, Li S, Li Q, Dong H. Evaluation of the marginal excess cement and retention force of implant-supported zirconia crowns with various vent designs under different cement application patterns. J Esthet Restor Dent. 2021. doi:10.1111/jerd.12842

8. Tanimura R, Suzuki S. Comparison of access-hole filling materials for screw retained implant prostheses: 12-month in vivo study. Int J Implant Dent. 2017;3(1):19. doi:10.1186/s40729-017-0076-4

9. Mallmann F, Rosa L, Borba M, Della Bona A. Effect of screw-access hole and mechanical cycling on fracture load of 3-unit implant-supported fixed dental prostheses. J Prosthet Dent. 2018;119(1):124-131. doi:10.1016/j.prosdent.2017.01.016

10. Malpartida-Carrillo V, Tinedo-Lopez PL, Ortiz-Culca F, Guerrero ME, Amaya-Pajares SP. Techniques for retrievability and for registering screw access holes in cement-retained implant-supported prostheses: a scoping review of the literature. J Prosthet Dent. 2020;123(3):427-433. doi:10.1016/j.prosdent.2019.03.011

11. Taylor RC, Ghoneim AS, McGlumphy EA. An esthetic technique to fill screw-retained fixed prostheses. J Oral Implantol. 2004;30(6):384-385. doi:10.1563/0681.1 
12. Lv XL, Qian SJ, Qiao SC, Gu YX, Lai HC, Shi JY. Clinical, radiographic, and immunological evaluation of angulated screw-retained and cemented single-implant crowns in the esthetic region: a 1-year randomized controlled clinical trial. Clin Implant Dent Relat Res. $2021 ; 23(5): 692-702$. doi:10.1111/cid.13035

13. Shahmiri R, Standard OC, Hart JN, Sorrell CC. Optical properties of zirconia ceramics for esthetic dental restorations: a systematic review. J Prosthet Dent. 2018;119(1):36-46. doi:10.1016/j.prosdent.2017.07.009

14. Dong H, Zhou N, Liu H, et al. Satisfaction analysis of patients with single implant treatments based on a questionnaire survey. Patient Prefer Adherence. 2019;13:695-704. doi:10.2147/PPA.S201088

15. Pollini A, Morton D, Arunyanak SP, Harris BT, Lin WS. Evaluation of esthetic parameters related to a single implant restoration by laypeople and dentists. J Prosthet Dent. 2020;124(1):94-99. doi:10.1016/j.prosdent.2019.08.017

16. Kabeya K, Satoh H, Hori S, Sawada Y. Experimental study on patient preferences regarding the shape and size of medical tablets and capsules using three-dimensionally printed plastic model formulations. Patient Prefer Adherence. 2021;15:863-870. doi:10.2147/PPA.S306582

17. Al-Dosari A, Al-Rowis R, Moslem F, Alshehri F, Ballo AM. Esthetic outcome for maxillary anterior single implants assessed by different dental Specialists. J Adv Prosthodont. 2016;8(5):345-353. doi:10.4047/jap.2016.8.5.345

18. Honda J, Komine F, Kamio S, Taguchi K, Blatz MB, Matsumura H. Fracture resistance of implant-supported screw-retained zirconia-based molar restorations. Clin Oral Implants Res. 2017;28(9):1119-1126. doi:10.1111/clr.12926

19. Jimenez RA, Vargas-Koudriavtsev T. Effect of preseating, screw access opening, and vent holes on extrusion of excess cement at the crown-abutment margin and associated tensile force for cement-retained implant restorations. Int J Oral Maxillofac Implants. 2016;31 (4):807-812. doi:10.11607/jomi.4143

20. Lee JH, Yang SE, Lee J, Lee SY. Influence of luting materials and methods and the restoration surface on the amount of cement remnants in implant restorations. J Oral Implantol. 2019;45(4):301-307. doi:10.1563/aaid-joi-D-18-00283

21. Korsch M, Marten SM, Walther W, Vital M, Pieper DH, Dotsch A. Impact of dental cement on the peri-implant biofilm-microbial comparison of two different cements in an in vivo observational study. Clin Implant Dent Relat Res. 2018;20(5):806-813. doi:10.1111/cid.12650

22. Assenza B, Artese L, Scarano A, et al. Screw vs cement-implant-retained restorations: an experimental study in the beagle. Part 2. Immunohistochemical evaluation of the peri-implant tissues. J Oral Implantol. 2006;32(1):1-7. doi:10.1563/754.1

23. Zaugg LK, Zehnder I, Rohr N, Fischer J, Zitzmann NU. The effects of crown venting or pre-cementing of CAD/CAM-constructed all-ceramic crowns luted on YTZ implants on marginal cement excess. Clin Oral Implants Res. 2018;29(1):82-90. doi:10.1111/clr.13071

24. Begum Z, Sonika R, Pratik C. Effect of different cementation techniques on retained excess cement and uniaxial retention of the implant-supported prosthesis: an in vitro study. Int J Oral Maxillofac Implants. 2014;29(6):1333-1337. doi:10.11607/jomi.3724

25. Patel D, Invest JC, Tredwin CJ, Setchell DJ, Moles DR. An analysis of the effect of a vent hole on excess cement expressed at the crown-abutment margin for cement-retained implant crowns. J Prosthodont. 2009;18(1):54-59. doi:10.1111/j.1532-849X.2008.00374.x

26. Meijndert CM, Raghoebar GM, Vissink A, Meijer HJA. Alveolar ridge preservation in defect sockets in the maxillary aesthetic zone followed by single-tooth bone level tapered implants with immediate provisionalization: a 1-year prospective case series. Int J Implant Dent. 2021;7(1):18. doi:10.1186/s40729-021-00292-4

27. Schwedhelm ER, Lepe X, Aw TC. A crown venting technique for the cementation of implant-supported crowns. J Prosthet Dent. 2003;89 (1):89-90. doi:10.1067/mpr.2003.66

28. Haas RC, Haas SE. Cement shield membrane technique to minimize residual cement on implant crowns: a dental technique. $J$ Prosthet Dent. 2020;123(2):223-227. doi:10.1016/j.prosdent.2019.03.017

29. Hess TA. A technique to eliminate subgingival cement adhesion to implant abutments by using polytetrafluoroethylene tape. $J$ Prosthet Dent. 2014;112(2):365-368. doi:10.1016/j.prosdent.2013.06.026

30. Seo CW, Seo JM. A technique for minimizing subgingival residual cement by using rubber dam for cement-retained implant crowns. $J$ Prosthet Dent. 2017;117(2):327-328. doi:10.1016/j.prosdent.2016.08.024

31. Cruz MA, Sorenson JA, Johnson WK. Effect of venting and seating techniques on the cementation of complete coverage restorations. Oper Dent. 2008;33(6):690-695. doi:10.2341/08-19

32. Vindasiute E, Puisys A, Maslova N, Linkeviciene L, Peciuliene V, Linkevicius T. Clinical factors influencing removal of the cement excess in implant-supported restorations. Clin Implant Dent Relat Res. 2015;17(4):771-778. doi:10.1111/cid.12170

33. Al-Johany SS, Al Amri MD, Al-Bakri AS, Al-Qarni MN. Effect of the unfilled space size of the abutment screw access hole on the extruded excess cement and retention of single implant zirconia crowns. J Prosthodont. 2019;28(2):179-184. doi:10.1111/jopr.12580

34. Al Amri MD, Al-Johany SS, Al-Qarni MN, Al-Bakri AS, Al-Maflehi NS, Abualsaud HS. Influence of space size of abutment screw access channel on the amount of extruded excess cement and marginal accuracy of cement-retained single implant restorations. J Prosthet Dent. 2018;119 (2):263-269. doi:10.1016/j.prosdent.2017.03.013

35. Corrales RJ. Effect of preseating on the extrusion of excess cement at the crown- abutment margin and the associated tensile force for cement-retained implant restorations. A pilot study. Odovtos - Int J Dent Sc. 2015;17(2):33. doi:10.15517/ijds.v17i2.20732

36. Gehrke P, Bleuel K, Fischer C, Sader R. Influence of margin location and luting material on the amount of undetected cement excess on CAD/CAM implant abutments and cement-retained zirconia crowns: an in-vitro study. BMC Oral Health. 2019;19(1):111. doi:10.1186/s12903-019-0809-2

37. Mihali S, Canjau S, Bratu E, Wang H-L. Utilization of ceramic inlays for sealing implant prostheses screw access holes: a case-control study. Int J Oral Maxillofac Implants. 2016;1142-1149. doi:10.11607/jomi.4733

38. Saboury A, Gooya A. Covering the screw-access holes of implant restorations in the esthetic zone: a clinical report. J Dent. 2014;11(6):715-720.

39. Kurt M, Ural C, Kulunk T, Sanal AF, Erkocak A. The effect of screw color and technique to fill access hole on the final color of screw-retained implant crowns. J Oral Implantol. 2011;37(6):673-679. doi:10.1563/AAID-JOI-D-10-00045.1

40. Schoenbaum TR, Wadhwani C, Stevenson RG. Covering the implant prosthesis screw access hole: a biological approach to material selection and technique. J Oral Implantol. 2017;43(1):39-44. doi:10.1563/aaid-joi-D-16-00119

41. Weininger B, McGlumphy E, Beck M. Esthetic evaluation of materials used to fill access holes of screw-retained implant crowns. J Oral Implantol. 2008;34(3):145-149. doi:10.1563/1548-1336(2008)34[145:EEOMUT]2.0.CO;2

42. Jonker BP, Wolvius EB, van der Tas JT, Tahmaseb A, Pijpe J. Esthetics and patient-reported outcomes of implants placed with guided bone regeneration and complete native bone: a prospective controlled clinical trial. Int J Oral Maxillofac Implants. 2020;35(2):406-414. doi:10.11607/ jomi. 7751 
43. Al Taki A, Khalesi M, Shagmani M, Yahia I, Al Kaddah F. Perceptions of altered smile esthetics: a comparative evaluation in orthodontists, dentists, and laypersons. Int J Dent. 2016;2016:7815274. doi:10.1155/2016/7815274

44. Falkensammer F, Loesch A, Krall C, Weiland F, Freudenthaler J. The impact of education on the perception of facial profile aesthetics and treatment need. Aesthetic Plast Surg. 2014;38(4):620-631. doi:10.1007/s00266-014-0329-z

45. Wolfart S, Lawrenz B, Schley JS, Kern M, Springer I. Composite images of upper front teeth-judgment of attractiveness and gender-specific correlation. $J$ Esthet Restor Dent. 2014;26(6):394-402. doi:10.1111/jerd.12088

46. Meffert RM. Esthetics versus function: is one more important than the other? Implant Dent. 2002;11(3):201. doi:10.1097/00008505-20020700000001

47. Taibah SM. Dental professionalism and influencing factors: patients' perception. Patient Prefer Adherence. 2018;12:1649-1658. doi:10.2147/PPA. S172788

48. Saboury A, Mahshid M, Tabatabaian F, Moghadam L. Effect of screw access hole design on the fracture resistance of implant-supported zirconia-based restorations. $J$ Esthet Restor Dent. 2018;30(6):545-550. doi:10.1111/jerd.12422

49. Du L, Li Z, Chang X, et al. Effects of the screw-access hole diameter on the biomechanical behaviors of 4 types of cement-retained implant prosthodontic systems and their surrounding cortical bones: a 3D finite element analysis. Implant Dent. 2018;27(5):555-563. doi:10.1097/ ID.0000000000000812

50. Schoenbaum TR, Chang YY, Stevenson RG. Screw access mark for cemented implant crowns: a universal technique to simplify retrievability. J Oral Implantol. 2018;44(1):71-73. doi:10.1563/aaid-joi-D-17-00147

\section{Publish your work in this journal}

Patient Preference and Adherence is an international, peer-reviewed, open access journal that focusing on the growing importance of patient preference and adherence throughout the therapeutic continuum. Patient satisfaction, acceptability, quality of life, compliance, persistence and their role in developing new therapeutic modalities and compounds to optimize clinical outcomes for existing disease states are major areas of interest for the journal. This journal has been accepted for indexing on PubMed Central. The manuscript management system is completely online and includes a very quick and fair peer-review system, which is all easy to use. Visit http://www.dovepress.com/testimonials.php to read real quotes from published authors.

Submit your manuscript here: https://www.dovepress.com/patient-preference-and-adherence-journal 